\title{
Effects of Biodanza on Stress, Depression, and Sleep Quality in University Students
}

\author{
María Mar López-Rodríguez, PhD, Ingrid Baldrich-Rodríguez, MSc, Alicia Ruiz-Muelle, MSc, \\ Alda Elena Cortés-Rodríguez, MSc, Teresa Lopezosa-Estepa, MSc, and Pablo Roman, MSc ${ }^{1,5}$
}

\begin{abstract}
Background: The existing literature shows dance to be an innovative and successful form of stress management. Previous research indicates that Biodanza is able to increase well-being and personal resources and prevent stress. However, Biodanza has not yet been empirically tested as a possible therapy for application outside the clinical context in young adults with perceived stress.

Objectives: This study aimed to determine the effectiveness of Biodanza in reducing symptoms of perceived stress and depression and in promoting sleep quality in young adults, comparing the changes with those observed in a control group.

Design: Randomized controlled trial.

Settings/Location: This study was carried out at the Faculty of Health Sciences of the University of Almería.

Subjects: One hundred and twenty-one university students with perceived stress were randomly placed into either a Biodanza group or a wait-list control group.

Intervention: Study participants attended Biodanza sessions for $90 \mathrm{~min}$ a week, over a period of 4 weeks.

Outcome measures: Depression, perceived stress, and sleep quality were assessed both before and after intervention.

Results: Ninety-five participants completed the program and were included in the statistical analysis. Significant differences in perceived stress $[t(93)=2.136 ; p=0.015]$ and depression $[t(93)=2.738 ; p=0.000]$ were observed after the Biodanza period. Pre/post analysis found that Biodanza also had a significant effect on depression (Cohen $d=1.88 ; p<0.05$ ) and perceived stress (Cohen $d=0.79 ; p<0.05$ ).

Conclusion: The Biodanza program is an effective stress management strategy for students. The results of this study showed Biodanza to have a positive effect on perceived stress and depression in young adults. This demonstrates how artistic, collaborative, and psychophysical interventions are an effective means of preventing and managing these problems in university students.
\end{abstract}

Keywords: therapeutic dance, Biodanza, perceived stress, depression, sleep quality, university students

\section{Introduction}

$\mathbf{R}$ ECENT FIGURES REVEAL that many students in higher education report symptoms of mental disorders, which can negatively affect their physical, emotional, cognitive, and interpersonal functioning. Approximately $50 \%$ of students experience significant levels of stress, generalized anxiety, or depression. ${ }^{1-4}$
Psychiatric disorders are also common among university students in Spain, with a substantial portion of students screening positively for major depression. According to Balanza et al., $65.9 \%$ of college students are likely to have anxiety and/or depression, $55.7 \%$ suffer from some form of anxiety disorder, and $63.8 \%$ may suffer from clinical depression. In general, results among Spanish students are comparable to those observed in other countries. ${ }^{5-7}$

\footnotetext{
${ }^{1}$ Department of Nursing, Physiotherapy and Medicine, University of Almería, Almería, Spain.

${ }^{2}$ Vithas Virgen del Mar Hospital, Almería, Spain.

${ }^{3}$ Faculty of Health Sciences, University of Almería, Almería, Spain.

${ }^{4}$ St. George's Hospital, London, United Kingdom.

${ }^{5}$ Department of Nursing, Universitat Jaume I, Castellón, Spain.
} 
The prevalence of test anxiety has been estimated to be as high as $35 \%$ among college students, and it has also been linked to lower academic performance. Common stressors in students' lives include the constant pressure to succeed, competition with peers, lack of free time, examinations, and having to manage the basic demands of everyday life. Moreover, certain personality traits such as perfectionism and shyness may be correlated with psychopathologies observed within the student population. $1,2,8-14$

Although proper sleep hygiene has proved to be important for mental health, complaints of sleep problems are extremely common among university students. Research has linked these issues to depression and anxiety in young adults. The sleep patterns of university students are often vastly different from those of others within the same age group. Therefore, it is important to address any irregularities when promoting health education activities. ${ }^{2,15-17}$

Perceived stress was the main reported cause of sleeping difficulties. Students suffering from low-quality sleep also reported more frequent use of drugs and alcohol. ${ }^{13,16}$

While the high prevalence of mental health problems among university students highlights a clear need for accessible treatment options, the majority of students with moderately severe to severe depression do not receive any psychiatric therapy. Downs and Eisenberg reported that low treatment rates are correlated with help-seeking behaviors among students, and only slightly over half of students with suicidal ideation receive therapy. According to the literature, the most common coping strategies used by students to manage stress and depression are exercising, spending time with family and friends, watching TV, and/or drinking alcohol. ${ }^{2,12,18,19}$

There is evidence that exercise and cognitive-, behavioral-, and mindfulness-based approaches are effective in reducing stress and depression among university students. However, in practice, medication is the form of treatment that is most often used. ${ }^{14,20-23}$

Besides being a physical activity, dance also incorporates emotional, cognitive, and cultural aspects involving social interaction, sensory stimulation, motor coordination, and music. Some studies ${ }^{24-31}$ use "dance therapy" (or "dance intervention") to refer to rhythmic and patterned body movements that are performed to music, while other authors define dance movement therapy as a process that improves one's emotional, social, cognitive, and physical integration. $^{20,32}$ Nevertheless, given their similarity, Koch et al. ${ }^{33}$ analyze both forms of treatment within the same review. Although these therapies are yet to be thoroughly studied, and nonmotor symptoms have often been neglected in favor of motor symptoms, empirical evidence suggests that they may help to decrease the symptoms of depression and anxiety and improve quality of life, well-being, mood, affect, and body image. As a result, some findings promote dance as an innovative and successful treatment for stress and depression that may help maximize the effects of usual treatments. ${ }^{20,24-33}$

According to Toro, ${ }^{34}$ Biodanza is a "human integration system of organic renewal, affective re-education, and of relearning of Life's original functions" (p. 39). In contrast to dance and dance movement therapy, Biodanza involves leading "vivencias" through music, singing, movements, and group interactions. Sessions are always performed as a group, combining different motor, sensory, and emotional exercises. $^{34}$
Prior research ${ }^{35-38}$ indicates that Biodanza helps reduce the pain and impact of fibromyalgia by reducing stress, enhancing social skills, and increasing sleep quality and overall wellbeing. However, Biodanza is yet to be empirically tested as a possible treatment for perceived stress in young adults.

Based on the limited literature regarding Biodanza and other related interventions, including dance and dance movement therapy, it was hypothesized that undertaking a Biodanza program over the academic term would benefit students in the intervention group by improving or avoiding the worsening of sleep quality, stress, and depression levels. The hypothesis also predicted that these indicators would worsen in students who did not receive treatment. Biodanza participants were predicted to show improved levels of stress, depression, and sleep quality after treatment, in comparison with the control group. This study aims to examine the effects of a 1-month Biodanza program on stress, depression, and sleep quality over the academic term, using a sample of university students with perceived stress and comparing these changes with those observed in the control group.

\section{Materials and Methods}

\section{Participants}

Volunteers were recruited from among students with perceived stress attending the University of Almería, using advertisements placed around the campus and displayed on the university's website. Respondents were invited to participate in a randomized clinical trial evaluating Biodanza in comparison with a wait-list control group; participants were informed that they could be allocated to either one of these two groups.

Inclusion criteria stipulated that participants must be at least 18 years old and a university student with self-reported psychological distress. Participants in the intervention group were required to attend four sessions. Exclusion criteria included psychiatric illness and serious physical disability or limitations.

Sample size determination was carried out based on previous studies. $^{27,32,37}$ This generated a sample size of at least 60 participants per group, with an estimated dropout rate of $30 \%$.

The recruitment was finished once 130 people had responded to the advertisements. Selected participants completed baseline questionnaires before randomization to avoid any anticipatory effects. After completing the initial pretest, those who met the inclusion criteria $(n=121)$ were randomly assigned to a Biodanza $(n=60)$ or wait-list control group $(n=61)$.

After randomization, 52 participants in the intervention group commenced the program, with 8 people unable to start the intervention due to work or other commitments. In addition, nine people failed to attend any session, and one of them did not complete the posttest questionnaires properly. In addition, seven participants in the control group were excluded after the posttest due to incomplete questionnaires (Fig. 1).

The study enabled subjects in the control group to participate in the Biodanza sessions after the follow-up period.

\section{Procedures and interventions}

Before inclusion in the study, participants were provided with detailed information regarding their right to withdraw at any time and the voluntary nature of their participation; all subjects provided their written informed consent. This study was conducted with full institutional human research ethics 


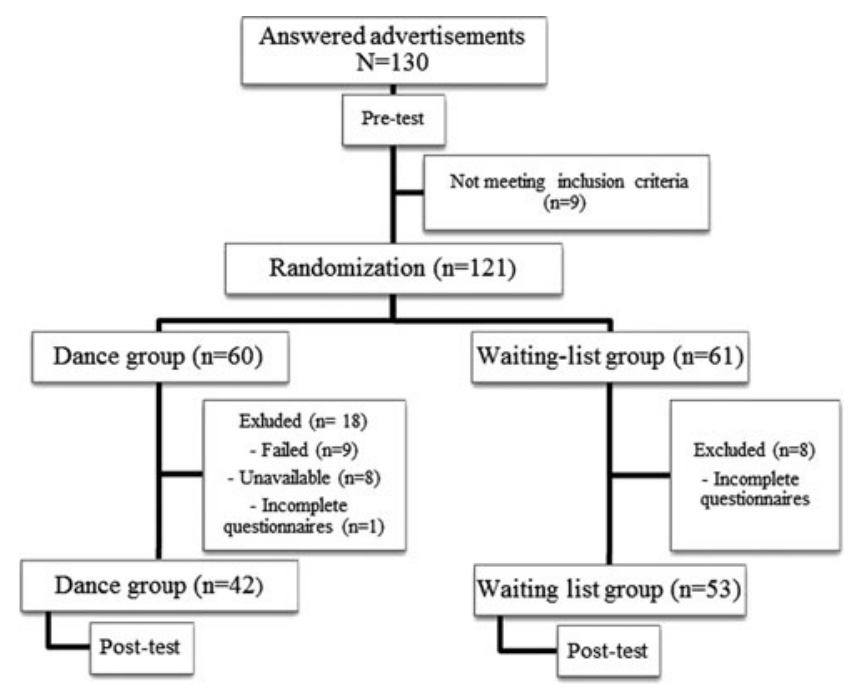

FIG. 1. Flow of subjects.

approval from the University of Almería, in accordance with the ethical guidelines of the Declaration of Helsinki.

The intervention group received four Biodanza sessions once a week, over the course of 1 month. These sessions were led by an experienced facilitator trained at a school endorsed by the International Biocentric Foundation (IBF). ${ }^{39}$

Each session lasted $90 \mathrm{~min}$. At the beginning of every Biodanza session, participants were encouraged to talk about themselves or their experiences. Afterward, they had a 10-min warm-up period with music and low-intensity movements in the welcome round, followed by $40 \mathrm{~min}$ of more active movements, including walking, dancing, or exercising, and finishing up with a 10-min final celebration round. At the end of each session, participants were asked to share their experiences. Each session allowed a maximum of 15 participants. The dance movements were based on natural human movements such as walking, jumping, or stretching; expressions involving "link rituals" such as shaking hands, hugging, or stroking; and archetypical gestures, which are original gestures of human expression belonging to different cultures. ${ }^{34}$

Participants in the wait-list control group were asked to continue their lives as normal during this period (close to final examinations in June), avoiding any other closely related activities such as other supportive group programs, dance classes, or physical activity with music. In addition, during the posttest, control group subjects were asked about any activities they had engaged in over the last month to exclude them from the study.

The questionnaires were completed online. Participants in the intervention group completed a survey before their first session (pretest) and 1 week after their fourth session (posttest). Subjects in the control group completed pre- and posttests during the same week as participants in the Biodanza group. As a result, subjects in both groups were at the same pre-examination phase of the academic term and therefore shared a common stressor.

\section{Measures}

The online survey included the Pittsburgh Sleep Quality Index (PSQI), Perceived Stress Scale (PSS), and Center for
Epidemiologic Studies Depression Scale (CES-D). During the pretest, participants were asked to provide demographic information and describe their exercise habits over the past month.

A Spanish version of the PSQI was used. This questionnaire differentiates between "poor" and "good" quality of sleep. It includes 19 items divided into seven different areas: subjective sleep quality, sleep onset latency, sleep duration, habitual sleep efficiency, sleep disturbances, use of sleep medication, and daytime dysfunction over the past month. Scoring is based on a Likert scale of $0-3$, with a score of 3 reflecting the negative extreme. A global score greater than 5 (from a total range of $0-21$ ) is indicative of a poor-quality sleeper, whereas a score of 5 or less is indicative of a goodquality sleeper. The internal consistency coefficient of the PSQI, as estimated by Cronbach's alpha, is $0.73 .^{40}$

The PSS includes questions intended to evaluate the current level of stress experienced by the subject. It is a brief scale, consisting of only 14 items to measure how unpredictable, uncontrollable, and overloaded individuals perceive their current life circumstances to be. Moreover, because the PSS assesses general beliefs about perceived stress without providing subjects with a list of specific life events, scores are not biased by event content or by differential recall of past life experiences. Scores range from 0 to 56 , with higher scores indicating a greater level of perceived stress. The European Spanish version of the PSS (14 items) demonstrated adequate reliability (internal consistency, $\alpha=0.81$; test-retest, $r=0.73$ ), validity, and sensitivity. ${ }^{41}$

The CES-D is a self-report inventory containing 20 items scored by respondents to indicate the frequency of symptoms over the previous week. It employs a scale of 0 (less than a day), 1 (1-2 days), 2 (2-3 days), and 3 (5-7 days). The CES-D includes a wide spectrum of noted symptoms, which makes it useful for assessing levels of distress in addition to depression. A score of 16 or higher indicates the likely presence of distress. Epidemiologic research in Spain has demonstrated the validity and reliability (internal consistency, $\alpha=0.85$ ) of the CES-D (range $=0-60){ }^{42}$

\section{Data analysis}

SPSS version 20.0 was used for statistical analysis. Key baseline demographic variables and pretest measures were compared between groups using independent $t$-tests for continuous data and chi-squared tests for categorical data. To answer the hypotheses, $t$-tests were used for paired or independent samples when appropriate. Within-group comparisons were carried out to explore the effects of a 1month Biodanza program, as per the study objectives. Between-group analysis was used to compare these changes with those observed in the control group.

A $p$-value of $p<0.05$ was considered significant in all tests.

Cohen's $d$ reflects the standardized between-group or within-group difference, with values of $0.2,0.5$, and 0.8 denoting small, medium, and large effect sizes, respectively. ${ }^{43-45}$

\section{Results}

The study involved participants $(n=95)$ ranging from 18 to 45 years old $(M=22.07 ; \mathrm{SD}=4.71)$, most of whom were women $(74.7 \%)$. The majority of participants in the sample had not been diagnosed with any mental disorder (92.6\%) and considered studying their main source of stress (76.8\%). 
Table 1. Sociodemographic Data of Students

\begin{tabular}{|c|c|c|c|c|c|}
\hline & & Groups & & & \\
\hline & $\begin{array}{c}T G \\
\mathrm{n}=95 \\
\text { Mean } \pm S D / \mathrm{n}(\%)\end{array}$ & $\begin{array}{c}W G \\
\mathrm{n}=53 \\
\text { Mean } \pm S D / \mathrm{n}(\%)\end{array}$ & $\begin{array}{c}B G \\
\mathrm{n}=42 \\
\text { Mean } \pm S D / \mathrm{n}(\%)\end{array}$ & $\chi^{2}$ & $\mathrm{p}$ \\
\hline Age (years) & $22.33 \pm 4.12$ & $21.77 \pm 4.53$ & $22.45 \pm 4.96$ & $-0.264^{\mathrm{a}}$ & 0.792 \\
\hline $\begin{array}{l}\text { Sex } \\
\quad \text { Male } \\
\text { Female }\end{array}$ & $\begin{array}{l}24(25.3 \%) \\
71(74.7 \%)\end{array}$ & $\begin{array}{l}14(26.4 \%) \\
39(73.6 \%)\end{array}$ & $\begin{array}{l}10(23.8 \%) \\
32(76.2 \%)\end{array}$ & 0.084 & 0.772 \\
\hline $\begin{array}{l}\text { Exercise day } \\
0 \\
1 \\
2 \\
3 \\
4 \\
5 \\
6 \\
7\end{array}$ & $\begin{aligned} 3 & (3.2 \%) \\
23 & (24.2 \%) \\
20 & (21.1 \%) \\
21 & (22.1 \%) \\
19 & (20.0 \%) \\
5 & (5.3 \%) \\
3 & (3.2 \%) \\
1 & (1.1 \%)\end{aligned}$ & $\begin{aligned} & (5.7 \%) \\
13 & (24.5 \%) \\
11 & (20.8 \%) \\
11 & (20.8 \%) \\
11 & (20.8 \%) \\
2 & (3.8 \%) \\
2 & (3.8 \%) \\
0 & (0.0 \%)\end{aligned}$ & $\begin{aligned} 0 & (0.0 \%) \\
10 & (23.8 \%) \\
9 & (21.4 \%) \\
10 & (23.8 \%) \\
8 & (19.0 \%) \\
3 & (7.1 \%) \\
1 & (2.4 \%) \\
1 & (2.4 \%)\end{aligned}$ & 4.432 & 0.729 \\
\hline $\begin{array}{l}\text { Mental disor } \\
\text { No } \\
\text { Yes }\end{array}$ & $\begin{array}{r}88(92.6 \%) \\
7(7.4 \%)\end{array}$ & $\begin{aligned} 51 & (96.2 \%) \\
2 & (3.8 \%)\end{aligned}$ & $\begin{array}{r}37(88.1 \%) \\
5(11.9 \%)\end{array}$ & 2.270 & 0.132 \\
\hline $\begin{array}{l}\text { Source of st } \\
\text { Studies } \\
\text { Family } \\
\text { None } \\
\text { Health } \\
\text { Work }\end{array}$ & $\begin{array}{c}73(76.8 \%) \\
7(7.4 \%) \\
5(5.3 \%) \\
1(1.1 \%) \\
9(9.5 \%)\end{array}$ & $\begin{array}{c}38(71.7 \%) \\
4(7.5 \%) \\
4(7.5 \%) \\
1(1.9 \%) \\
6(11.3 \%)\end{array}$ & $\begin{array}{c}35(83.3 \%) \\
3(7.1 \%) \\
1(2.4 \%) \\
0(0.0 \%) \\
3(7.1 \%)\end{array}$ & 2.830 & 0.587 \\
\hline $\begin{array}{l}\text { Use compleı } \\
\text { No } \\
\text { Yes }\end{array}$ & $\begin{array}{l}\text { techniques } \\
91(95.8 \%) \\
4(4.2 \%)\end{array}$ & $\begin{array}{c}50(94.3 \%) \\
3(5.7 \%)\end{array}$ & $\begin{array}{c}41(97.6 \%) \\
1(2.4 \%)\end{array}$ & 0.625 & 0.429 \\
\hline $\begin{array}{l}\text { Use dance } \\
\text { No } \\
\text { Yes }\end{array}$ & $\begin{array}{c}87(91.6 \%) \\
8(8.4 \%)\end{array}$ & $\begin{aligned} 51 & (96.2 \%) \\
2 & (3.8 \%)\end{aligned}$ & $\begin{array}{r}36(85.7 \%) \\
6(14.3 \%)\end{array}$ & 3.358 & 0.067 \\
\hline
\end{tabular}

${ }^{\mathrm{a}} t$-student.

BG, Biodanza group; SD, standard deviation; TG, total group; WG, waiting-list control group.

Most participants (87.4\%) exercised between once and four times a week, and the majority had not previously used any complementary therapy $(95.8 \%)$ or dance $(91.6 \%)$ to control stress. Although there did not appear to be any statistically significant differences between groups in the use of dance, a higher percentage of dance use was observed in the intervention group (Table 1).

According to the PSQI suggested cutoff, the pretest found 48 participants $(40.0 \%)$ to be poor-quality sleepers. The CES-D cutoffs found that 69 participants $(72.6 \%)$ reported symptoms of depression at the beginning of the study, with a mean score of greater than 16 .

The correlations between variables indicated that participants were more likely to experience lower sleep quality when they also reported high stress $(r=0.315 ; p<0.01)$ or depression $(r=0.386 ; p<0.01)$. Those reporting depressive symptoms were more likely to report stress $(r=0.677$; $p<0.01)$ (Table 2).

\section{Group comparisons}

At baseline, no significant differences were found between the Biodanza and wait-list control groups (Table 1).
No significant differences between groups were observed in stress, depression, or sleep quality at the pretest. After the Biodanza period, however, there were significant differences between groups in perceived stress $[t(93)=2.136$; $p=0.035$; Cohen's $d=0.44]$ and depression $[t(93)=2.738$; $p=0.007$; Cohen's $d=0.56]$. Conversely, no significant differences in sleep quality were observed $[t(93)=0.432$; $p=0.666$; Cohen's $d=0.09$ ]. Nevertheless, there were some posttest differences in the subscale "subjective sleep quality" from the PSQI $[t(93)=2.311 ; p=0.023$; Cohen's $d=0.48$ ] (Table 3).

Table 2. Correlations Between Variables AT BASELINe $(N=95)$

\begin{tabular}{llll}
\hline & \multicolumn{1}{c}{$P S S$} & \multicolumn{1}{c}{ CES-D } & \multicolumn{1}{c}{ PSQI } \\
\hline PSS & 1.000 & $0.544^{* *}$ & $0.266^{* *}$ \\
CES-D & $0.544^{* *}$ & 1.000 & $0.394^{* *}$ \\
PSQI & $0.266^{* *}$ & $0.394^{* *}$ & 1.000 \\
\hline
\end{tabular}

$* * p<0.01$ (two tailed).

CES-D, Center for Epidemiologic Studies Depression Scale; PSQI, Pittsburgh Sleep Quality Index; PSS, Perceived Stress Scale. 
Table 3. Between-Group Effects

\begin{tabular}{|c|c|c|c|c|c|}
\hline & & Groups & & & \\
\hline & $\begin{array}{l}T G(\mathrm{n}=95) \\
\text { Mean } \pm S D\end{array}$ & $\begin{array}{c}W G(n=53) \\
M e a n \pm S D\end{array}$ & $\begin{array}{l}B G(\mathrm{n}=42) \\
\text { Mean } \pm S D\end{array}$ & $\mathrm{t}$ & $\mathrm{p}$ \\
\hline Pretest & & & & & \\
\hline PSS & $25.34 \pm 8.10$ & $25.26 \pm 7.52$ & $25.43 \pm 8.87$ & -0.098 & $\begin{array}{l}0.922 \\
0.074\end{array}$ \\
\hline CES-D & $21.74 \pm 11.48$ & $19.81 \pm 10.12$ & $24.17 \pm 12.71$ & -1.811 & 0.074 \\
\hline PSQI & $5.99 \pm 2.93$ & $5.58 \pm 2.59$ & $6.50 \pm 3.28$ & -1.520 & 0.132 \\
\hline Subjective quality & $1.18 \pm 0.63$ & $1.09 \pm 0.59$ & $1.28 \pm 0.67$ & 0.152 & 0.152 \\
\hline Latency & $1.43 \pm 1.00$ & $1.38 \pm 0.94$ & $1.50 \pm 1.08$ & -0.588 & 0.558 \\
\hline Duration & $0.46 \pm 0.85$ & $0.36 \pm 0.83$ & $0.59 \pm 0.85$ & -1.357 & 0.178 \\
\hline Efficiency & $0.57 \pm 0.83$ & $0.45 \pm 0.69$ & $0.71 \pm 0.97$ & -1.473 & 0.145 \\
\hline Disturbances & $1.13 \pm 0.53$ & $1.09 \pm 0.56$ & $1.17 \pm 0.49$ & -0.658 & 0.512 \\
\hline Medication & $0.10 \pm 0.39$ & $0.13 \pm 0.44$ & $0.07 \pm 0.34$ & 0.734 & 0.465 \\
\hline Dysfunction & $1.11 \pm 0.78$ & $1.07 \pm 0.78$ & $1.17 \pm 0.79$ & -0.561 & 0.576 \\
\hline Posttest & & & & & \\
\hline PSS & $23.59 \pm 10.13$ & $25.53 \pm 9.21$ & $21.14 \pm 10.79$ & 2.136 & 0.035 \\
\hline CES-D & $15.29 \pm 9.55$ & $17.60 \pm 9.84$ & $12.38 \pm 8.40$ & 2.738 & 0.007 \\
\hline PSQI & $5.77 \pm 2.98$ & $5.89 \pm 3.20$ & $5.62 \pm 2.72$ & .432 & 0.666 \\
\hline Subjective quality & $1.17 \pm 0.65$ & $1.30 \pm 0.57$ & $1.00 \pm 0.69$ & 2.311 & 0.023 \\
\hline Latency & $1.19 \pm 0.97$ & $1.15 \pm 1.08$ & $1.24 \pm 0.82$ & -0.447 & 0.656 \\
\hline Duration & $0.51 \pm 0.85$ & $0.53 \pm 0.95$ & $0.50 \pm 0.71$ & 0.161 & 0.873 \\
\hline Efficiency & $0.47 \pm 0.78$ & $0.45 \pm 0.84$ & $0.50 \pm 0.70$ & -0.290 & 0.772 \\
\hline Disturbances & $1.04 \pm 0.48$ & $1.00 \pm 0.52$ & $1.09 \pm 0.43$ & -0.956 & 0.341 \\
\hline Medication & $0.18 \pm 0.50$ & $0.18 \pm 0.55$ & $0.17 \pm 0.43$ & 0.210 & 0.834 \\
\hline Dysfunction & $1.20 \pm 0.79$ & $1.26 \pm 0.85$ & $1.12 \pm 0.70$ & 0.884 & 0.379 \\
\hline
\end{tabular}

\section{Pre/post comparisons}

The within-group comparison of the control group found no significant differences. However, results from the Biodanza group found statistically significant differences in de- pression $[t \quad(41)=6.026 ; p=0.000]$, perceived stress $[t$ $(41)=2.549 ; p=0.015]$, and subjective sleep quality $[t(41)=$ 2.218; $p=0.032]$. The effect size in the Biodanza group was medium for stress (Cohen's $d=0.79$ ), large for depression (Cohen's $d=1.88$ ), and small for total sleep quality score

Table 4. Within-Group Effects (Pre/Post Analysis)

\begin{tabular}{|c|c|c|c|c|c|c|}
\hline & \multicolumn{2}{|c|}{ Paired differences } & \multicolumn{2}{|c|}{$95 \%$ CI of the difference } & \multirow[b]{2}{*}{$\mathrm{t}$} & \multirow[b]{2}{*}{$\mathrm{p}$} \\
\hline & Mean & $S D$ & Lower & Upper & & \\
\hline \multicolumn{7}{|l|}{ WG } \\
\hline PSS & -0.26 & 8.84 & -2.70038 & 2.17207 & -0.218 & 0.829 \\
\hline CES-D & 2.20 & 8.29 & -0.07844 & 4.49353 & 1.938 & 0.058 \\
\hline PSQI & -0.30 & 3.13 & -1.16609 & 0.56231 & -0.701 & 0.486 \\
\hline Subjective quality & -0.20755 & 0.79320 & -0.42618 & 0.01109 & -1.905 & 0.062 \\
\hline Latency & 0.22642 & 1.08560 & -0.07281 & 0.52564 & 1.518 & 0.135 \\
\hline Duration & -0.16981 & 0.99491 & -0.44404 & 0.10442 & -1.243 & 0.220 \\
\hline Efficiency & 0.00000 & 0.96077 & -0.26482 & 0.26482 & 0.000 & 1.000 \\
\hline Disturbances & 0.09434 & 0.65821 & -0.08708 & 0.27576 & 1.043 & 0.302 \\
\hline Medication & -0.05660 & 0.66260 & -0.23924 & 0.12603 & -0.622 & 0.537 \\
\hline Dysfunction & -0.18868 & 0.96190 & -0.45381 & 0.07645 & -1.428 & 0.159 \\
\hline \multicolumn{7}{|l|}{$\mathrm{BG}$} \\
\hline PSS & 4.28 & 10.89 & 0.89065 & 7.68078 & 2.549 & 0.015 \\
\hline CES-D & 11.78 & 12.67 & 7.83585 & 15.73558 & 6.026 & 0.000 \\
\hline PSQI & 0.88 & 4.02 & -0.37350 & 2.13540 & 1.418 & 0.164 \\
\hline Subjective quality & 0.28571 & 0.83478 & 0.02558 & 0.54585 & 2.218 & 0.032 \\
\hline Latency & 0.26190 & 1.30775 & -0.14562 & 0.66943 & 1.298 & 0.202 \\
\hline Duration & 0.09524 & 0.90553 & -0.18694 & 0.37742 & 0.682 & 0.499 \\
\hline Efficiency & 0.21429 & 1.29795 & -0.19018 & 0.61875 & 1.070 & 0.291 \\
\hline Disturbances & 0.07143 & 0.55843 & -0.10259 & 0.24545 & 0.829 & 0.412 \\
\hline Medication & -0.09524 & 0.37020 & -0.21060 & 0.02013 & -1.667 & 0.103 \\
\hline Dysfunction & 0.04762 & 0.96151 & -0.25201 & 0.34725 & 0.321 & 0.750 \\
\hline
\end{tabular}

CI, confidence interval. 
(Cohen's $d=0.44$ ). In the control group, negative small effect sizes were observed for stress (Cohen's $d=-0.06$ ) and sleep quality (Cohen's $d=-0.19$ ) (Table 4).

\section{Discussion}

This is the first randomized controlled trial to explore a Biodanza program as a possible therapeutic treatment for university students with perceived stress. In this study, statistical analysis demonstrated that Biodanza has a significant effect on stress and depression when compared with control conditions.

The hypothesis was partially supported, as the intervention group showed significant short-term reduction of stress and depression, but no changes in sleep quality. Furthermore, at posttest, the intervention group showed lower stress and depression levels when compared to the wait-list control group.

Participants in the Biodanza group reported a significant reduction in stress at posttest in comparison with the waitlist control group. Results from the intervention group also saw statistically significant differences pre- and postintervention. No statistically significant differences were observed in the wait-list control group, which showed a slight worsening of stress levels.

These outcomes are consistent with prior research indicating the positive effect of dance on anxiety and emotions in college students. ${ }^{30,31}$ Dance movement therapy on stress in patients with cancer ${ }^{43}$ and tango on people with selfreported depression, ${ }^{27}$ showed a small between-group effect size. Bräuninger ${ }^{32}$ demonstrated a small between-group effect size of dance movement therapy on anxiety in people with stress. These results are smaller than those obtained by Pylvänäinen et al. ${ }^{20}$ using this therapy on depressed adults with anxiety (a large between-group effect size), although their within-group effect size was considered medium.

Carbonell-Baeza et al. ${ }^{35}$ did not find Biodanza to have a significant impact on anxiety in patients with fibromyalgia. Conversely, Stück et al. ${ }^{38}$ showed positive effects on the self-regulatory aspects of stress reduction in healthy people following a very similar program.

Although Biodanza participants did not see a significant posttest reduction in their total PSQI score when compared with the control group, favorable changes were observed in the intervention group, while a slight worsening was reported in the control group. Furthermore, the subscale "subjective sleep quality" showed a significant improvement in the intervention group. Despite the fact that participants in this group did not show significant improvement in sleep quality after the therapy, the near-medium effect size suggests that a larger sample may in fact reveal further differences.

Studies measuring the effects of dance programs on improved sleep quality are limited. However, data similar to those of the current study were obtained using dance movement therapy in patients with cancer. ${ }^{43}$

The Biodanza group showed significant positive reductions in CES-D scores after intervention when compared with the control group, obtaining a medium effect size between groups. Moreover, in the pre/post test, statistically significant differences were found in the Biodanza group. The effect size on depression was considerably larger in the intervention group than the overall effect size reported for antidepressants in other studies. ${ }^{20}$
The findings of this study are similar to those observed when using tango therapy in people with self-reported depression $^{26}$ and dance therapy with depressed adult patients. ${ }^{17}$ These results are also consistent with those reached using dance movement therapy in patients with cancer, as shown by Ho et al., ${ }^{43}$ or those obtained by Bräuninger ${ }^{32}$ in people with stress. However, both studies obtained a smaller effects size. These and other studies ${ }^{20,32,43}$ demonstrate that dance movement therapy may reduce emotional distress by improving emotion-oriented coping strategies, the ability to interpret emotions, self-confidence, and affect. On the contrary, another study $^{35}$ using Biodanza did not show significant improvements in the depression levels of fibromyalgia patients.

Furthermore, it should be noted that the control group showed no statistically significant changes to levels of depression. One possibility is that the prospect of free lessons afterward may have influenced the responses of the group, or participants' moods may have been influenced by seasonal changes, a factor noted in several studies. ${ }^{46,47}$

The present study's limitations include those common to online surveys and self-reporting scales. Other possible limitations include the treatment expectations of participants in the intervention group. In addition, recruiting participants for dance therapy may have influenced the female-dominated gender makeup of the study, as women are generally more interested in dance activities. Finally, the higher tendency of subjects in the Biodanza group to have used dance therapy previously may have led to the treatment having a greater impact on this group.

\section{Conclusions}

The present study found that, when compared with a waitlist control group, Biodanza was a superior stress management strategy in a sample of university students taken during the academic term. These findings demonstrate the positive effects of Biodanza on self-reported stress in young adults. Furthermore, outcomes indicate that a brief Biodanza program was correlated with decreased levels of depression in university students during the academic term. On the contrary, the program did not result in significant improvements in sleep quality over the observed period of time.

In conclusion, a short-term Biodanza program may improve levels of stress and depression and may prevent anticipated worsening of sleep quality throughout the academic term. Biodanza is an effective method of managing depression and stress, and it may be an attractive, affordable option of first-line therapy for depression and stress management, a finding that is relevant for both health professionals and students. These results support the use of artistic, collaborative, and psychophysical interventions in the prevention and management of academic stress and depression in university students.

Future research is needed to incorporate multiple measurements that were not covered in this study, including physical fitness, cognitive functioning, academic performance, and drug use. Long-term treatment and follow-up are needed to fully understand the potential benefits of Biodanza over a period of time.

\section{Acknowledgments}

The authors thank the University of Almería and the students who participated in the collaboration of this study. 


\section{Author Disclosure Statement}

No competing financial interests exist.

\section{References}

1. Storrie K, Ahern K, Tuckett A. A systematic review: Students with mental health problems-A growing problem. Int J Nurs Pract 2010;16:1-6.

2. Tosevski DL, Milovancevic MP, Gajic SD. Personality and psychopathology of university students. Curr Opin Psychiatry 2010;23:48-52.

3. Jimenez C, Navia-Osorio PM, Diaz CV. Stress and health in novice and experienced nursing students. J Adv Nurs 2010;66:442-455.

4. Berenz EC, Kevorkian S, Chowdhury N, et al. Posttraumatic stress disorder symptoms, anxiety sensitivity, and alcoholuse motives in college students with a history of interpersonal trauma. Psychol Addict Behav 2016;30:755-763.

5. Vázquez FL, Torres Á, Otero P, Díaz O. Prevalence, comorbidity, and correlates of DSM-IV axis I mental disorders among female university students. J Nerv Ment Dis 2011;199:379-383.

6. Balanza S, Morales Moreno I, Guerrero J. Prevalencia de ansiedad y depresión en una población de estudiantes universitarios: Factores académicos y sociofamiliares asociados. Clin Salud 2009;20:177-187 [Spanish].

7. Vázquez FL, Blanco V. Symptoms of depression and related factors among Spanish university students. Psychol Rep 2006;99:583-590.

8. Chu JJ, Khan MH, Jahn HJ, Kraemer A. Only-child status in relation to perceived stress and studying-related life satisfaction among university students in China: A comparison with international students. PLoS One 2015;10:e0144947.

9. Burris JL, Brechting EH, Salsman J, Carison CR. Factors associated with the psychological well-being and distress of university students. J Am Coll Health 2009;57:536-543.

10. Hjeltnes A, Binder PE, Moltu C, Dundas I. Facing the fear of failure: An explorative qualitative study of client experiences in a mindfulness-based stress reduction program for university students with academic evaluation anxiety. Int J Qual Stud Health Well-being 2015;10:27990.

11. Chellew K, Evans P, Fornes-Vives J, et al. The effect of progressive muscle relaxation on daily cortisol secretion. Stress 2015;18:538-544.

12. Garlow S, Rosenberg J, Moore D, et al. Depression, desperation, and suicidal ideation in college students: Results from the American Foundation for Suicide Prevention College Screening Project and Emory University. Depress Anxiety 2008;25:482-488.

13. Keyes C, Eisenberg D, Perry G, et al. The relationship of level of positive mental health with current mental disorders in predicting suicidal behavior and academic impairment in college students. J Am Coll Health 2012;60: 126-133.

14. Regehr C, Glancy D, Pitts A. Interventions to reduce stress in university students: A review and meta-analysis. J Affect Disord 2013;148:1-11.

15. Doane LD, Gress-Smith JL, Breitenstein RS. Multi-method assessments of sleep over the transition to college and the associations with depression and anxiety symptoms. J Youth Adolesc 2015;44:389-404.

16. Assaad S, Costanian C, Haddad G, Tannous F. Sleep patterns and disorders among university students in Lebanon. J Res Health Sci 2014;14:198-204.
17. de Vasconcelos HC, Fragoso LV, Marinho NB, et al. Correlation between anthropometric indicators and sleep quality among Brazilian university students. Rev Esc Enferm USP 2013;47:852-859 [Spanish].

18. Lund H, Reider B, Whiting A, Prichard R. Sleep patterns and predictors of disturbed sleep in large population of college students. J Adolescent Health 2010;46:124-132.

19. Downs MF, Eisenberg D. Help seeking and treatment use among suicidal college students. J Am Coll Health 2012;60:104-114.

20. Pylvänäinen PM, Muotka JS, Lappalainen R. A dance movement therapy group for depressed adult patients in a psychiatric outpatient clinic: Effects of the treatment. Front Psychol 2015;6:980.

21. Rimer J, Dwan K, Lawlor DA, et al. Exercise for depression. Cochrane Database Syst Rev 2012;CD004366.

22. Teychenne M, Abbott G, Ball K, Salmon J. Prospective associations between sedentary behaviour and risk of depression in socio-economically disadvantaged women. Prev Med 2014;65:82-86.

23. Ida M, Ida I, Wada N, et al. A clinical study of the efficacy of a single session of individual exercise for depressive patients, assessed by the change in saliva free cortisol level. Biopsychosoc Med 2013;7:18.

24. Lakes KD, Marvin S, Rowley J, et al. Dancer perceptions of the cognitive, social, emotional and physical benefits of modern styles of partnerd dancing. Complement Ther Med 2016;26:117-122.

25. Marie-Sophie K, Stöckigt B, Keil T. Effects of dance therapy and ballroom dances on physical and mental illnesses: A systematic review. Art Psychother 2012;39:404-411.

26. Burges Watson D, Adams J, Azevedo LB, Haighton C. Promoting physical activity with a school-based dance mat exergaming intervention: Qualitative findings from a natural experiment. BMC Public Health 2016;16:609.

27. Pinniger R, Brown RF, Thorsteinsson EB, McKinley P. Argentine tango dance compared to mindfulness meditation and a waiting-list control: A randomised trial for treating depression. Complement Ther Med 2012;20:377-384.

28. Duberg A, Möller M, Sunvisson H. "I feel free": Experiences of a dance intervention for adolescent girls with internalizing problems. Int J Qual Stud Health Well-being 2016;11:31946.

29. Koch SC, Morlinghaus K, Fuchs T. The joy dance: Specific effects of a single dance intervention on psychiatric patients with depression. Arts Psychother 2007;34:340-349.

30. Krantz A, Pennebaker J. Expression of traumatic experiences through dance and writing: Psychological and health effects. Unpublished manuscript. [Internet]. 2001:1-34. Online document at: www.academia.edu/download/39848906/Krantz Pennebaker-_Expression_of_Traumatic_Experience_through_ Dance_and_Writing-_Psychological_and_Health_Effects.pdf disposition=inline\%3B\%20filename\%3DExpression_of Traumatic_Experience_throu.pdf, accessed March 15, 2017.

31. Leste A, Rust J. Effects of dance on anxiety. Am J Dance Ther 1990;12:19-25.

32. Bräuninger I. Dance movement therapy group intervention in stress treatment: A randomized controlled trial (RCT). Arts Psychother 2012;39:443-450.

33. Koch S, Kunz T, Lykou S, Cruz R. Effects of dance movement therapy and dance on health-related psychological outcomes: A meta-analysis. Arts Psychother 2014;41:46-64.

34. Toro R. Biodanza. Santiago de Chile: Cuarto Propio Ed., 2007:39 [Spanish]. 
35. Carbonell-Baeza A, Aparicio VA, Martins-Pereira CM, et al. Efficacy of Biodanza for treating women with fibromyalgia. J Altern Complement Med 2010;16:1191-1200.

36. D'Alencar BP, Mendes MM, Jorge MS, Guimarães JM. Biodance as process of existential renew for the elderly. Rev Bras Enferm 2008;61:608-614 [Portuguese].

37. López-Rodríguez MM, Fernández-Martínez M, MataránPeñarrocha GA, et al. Effectiveness of aquatic biodance on sleep quality, anxiety and other symptoms in patients with fibromyalgia. Med Clin (Barc) 2013;141:471-478 [Spanish].

38. Stück M, Villegas A, Bauer K, et al. Psycho-immunological process evaluation of Biodanza. Journal of Pedagogy and Psychology "Signum Temporis" 2011;2:99-113.

39. IBF: Internarional Biocentric Foundation [Internet]. Online document at: www.biodanza.org, accessed March 6, 2017.

40. Royuela A, Macías JA. Propiedades clinimétricas de la versión castellana del cuestionario de Pittsburgh. VigiliaSueño 1997:9:81-94 [Spanish].

41. Remor E. Psychometric properties of a European Spanish version of the Perceived Stress Scale (PSS). Span J Psychol 2006;9:86-93.

42. Soler J, Pérez-Sola V, Puigdemont D, et al. Validation study of the Center for Epidemiological Studies-Depression of a Spanish population of patients with affective disorders. Actas Luso Esp Neurol Psiquiatr Cienc Afines 1997;25: 243-249 [Spanish].

43. Ho RT, Fong TC, Cheung IK, et al. Effects of a short-term dance movement therapy program on symptoms and stress in patients with breast cancer undergoing radiotherapy: A randomized, controlled, single-blind trial. J Pain Symptom Manage 2016;51:824-831.

44. Bojner Horwitz E, Lennartsson AK, Theorell TP, Ullén F. Engagement in dance is associated with emotional competence in interplay with others. Front Psychol 2015;6:1096.

45. Cohen J. Statistical Power Analysis for the Behavioral Sciences, 2nd ed. Hillsdale, NJ: Lawrence Erlbaum Associates, 1988.

46. Rastad C, Ulfberg J, Sjödén PO. High prevalence of selfreported depressive mood during the winter season among Swedish senior high school students. J Am Acad Child Adolesc Psychiatry 2006;45:231-238.

47. Kristjánsdóttir J, Olsson GI, Sundelin C, Naessen T. Selfreported health in adolescent girls varies according to the season and its relation to medication and hormonal contraception-A descriptive study. Eur J Contracept Reprod Health Care 2013;18:343-354.

Address correspondence to:

Pablo Roman, $\mathrm{MSc}$

Departamento de Enfermería

Fisioterapia y Medicina

Universidad de Almeria

Ctra. Sacramento $s / n$

04120 La Cañada de San Urbano

Almería 04120

Spain

E-mail: pablo.roman@ual.es 